Hecht, F. and Kimberling, W. J. (1971). Patterns of D chromosome involvement in human (DqDq) and (DqGq) Robertsonian rearrangements. American fournal of Human Genetics, 23, 361367.

Jenab, M., Lade, R., Chiga, M., and Diehl, A. (1959). Cardiorespiratory syndrome of obesity in a child: case report and necropsy findings. Pediatrics, 24, 23.

Juul, J. and Dupont, A. (1967). Prader-Willi syndrome. Fournal of Mental Deficiency Research, 11, 12-22.

Landwirth, J., Schwartz, A. H., and Grunt, J. A. (1968). PraderWilli syndrome. American fournal of Diseases of Children, 116, 211-217.

Laurence, B. (1967). Hypotonia, mental retardation, obesity and cryptorchidism associated with dwarfism and diabetes in children. Archives of Disease in Childhood, 42, 126-139.

Lucas, M. (1969). Translocation between both members of chromosome pair number 15 causing recurrent abortions. Annals of Human Genetics, 32, 347-352.

Morgner, K. D., Geisthövel, W., Niedergerke, V., and Muhlen, A. (1974). Hypogonadismus infolge mandels an luteotropinreleasing hormon (LHRH) bei Prader-Labhart-Willi syndrome. Deutsche medizinische Wochenschrift, 99, 1196-1198.

Parra, A., Cervantes, C., and Schultz, R. B. (1973). Immunoreactive insulin and growth hormone responses in patients with Prader-Willi syndrome. Fournal of Pediatrics. 83, 587-593.

Pearson, K. D., Steinbach, H. L., and Bier, D. M. (1971). Roentgenographic manifestations of the Prader-Willi syndrome. Pediatric Radiology, 100, 369-377.

Pipes. P. L. and Horm, V. A. (1973). Weight control of children with Prader-Willi syndrome. Fournal of the American Dietetic Association, 62, 520-524.

Prader, A., Labhart, A., and Willi, H. (1956). Ein syndrom von adipositas kleinwudis, kryptorchismus und oligophrenic nach myatonicartigem zustard im neugeborenenalter. Schweizerische medizinische Wochenschrift, 86, 1260-1261.

Ridler, M., Garrod, O., and Berg, J. (1971). A case report of Prader-Willi Syndrome in a girl with a small extra chromosome. Acta Paediatrica Scandinavica, 60, 222-226.

Roget, J., Mouriquand, A., Bernard, Y., Patet, J., Jobert, J., and Gilly, C. (1965). Syndrome associant adiposite cryptorchide et retard mental accompagne d'une aberration chromosomique. Pédiatrie, 20, 295-300.

Schneider, H. J. and Zwellweger, H. (1968). Forme fruste of the Prader-Willi syndrome (HHHO) and balanced $\mathrm{D} / \mathrm{E}$ translocation. Helvetica Paediatrica Acta, 2, 128-136.

Seabright, M. A. (1971). Rapid banding technique for human chromosomes. Lancet, 2, 971-972.

Spencer, D. A. (1968). Prader-Willi syndrome. Lancet, 2, 571.

Stolecke, H., Huerne, C. J., and Tiling, E. (1974). Prader-LabhartWilli Syndrom: Klinische und psychopathologische untersuchungsergebnissie bei 4 eigenen patienten. Monatsschrift für Kinderheilkunde, 122, 10-17.

Zellweger, H. and Schneider, H. J. (1968). Syndrome of hypotoniahypomentia-hypogonadism-obesity (HHHO) or Prader-Will syndrome. American Fournal of Diseases of Children, 115, 588-598.

\section{Trisomy 13 in a female over 5 years of age*}

Summary. A case of simple trisomy 13, confirmed by G-banded chromosome analysis, is reported in a Caucasian female over 5 years of age.

* This work was supported in part by a grant from the Moody Foundation of Galveston, Texas.
There is no cytogenetic evidence available for mosaicism in the propositus or her parents.

The patient's salient clinical features are: profound mental and motor retardation; microcephaly with trigonocephaly; ear malformations; small, sunken eyes; unusual eyebrows; cleft lip and palate; bulbar nose; coloboma iris; polydactyly; unusual dermatoglyphic patterns; large adductor thumbs; enlarged great toes; multiple capillary haemangiomas; club feet; inguinal and umbilical hernias; hyperconvexed fingernails; and seizure disorder.

As with many other genetic disorders, it is constantly necessary to redefine specific disease entities in the light of newly available evidence. This is particularly true in the case of chromosomal disorders. Numerous advances in analytical cytogenetic techniques (Casperson, Zech, and Johansson, 1970; Moorhead et al, 1960; Seabright, 1971; Sumner, Evans, and Buckland, 1971) have revolutionized our ability to identify individual chromosomes reliably and rearrangements thereof. These important developments are comparatively recent; and, as a consequence, much of the literature detailing the various clinical features of different chromosomal syndromes was written without the benefit of these techniques of establishing unquestionable chromosomal diagnoses.

This is particularly true in the case of trisomy 13, which has been variously referred to as Patau's syndrome, trisomy D (13-15), or D1 trisomy syndrome. Most of the cases of D-group trisomy reported were discovered before the advent of $G$ and $Q$ banding, making accurate identification of the additional $\mathrm{D}$-group chromosome impossible in most instances. As a consequence, clinical characteristics of patients who may have had complete trisomy 14 or 15 , if either of these is a viable condition, could have been confused with those directly attributable to trisomy 13 . It is the purpose of this study to furnish information which may facilitate distinction of trisomy 13 from the other D-group trisomic conditions and to report extended survival and development beyond that previously reported in cases of complete trisomy 13.

\section{Case study}

We should like first to report the clinical findings in our patient. The propositus is a 5-year and 3-month- 
old Caucasian female who has 4 older, normal sibs. Her mother was 38; and the father, 42 , at the time of her birth which followed a 39-week, uncomplicated gestation. Labour was spontaneous and a birthweight of $2069 \mathrm{~g}$ was recorded.

Physical findings at birth. Congenital bilateral cleft lip and cleft palate; coloboma of left iris; a unilateral sixth digit; bilateral single palmar creases; adductor thumbs; multiple capillary haemangiomas; microcephaly; lowset, anomalous ears; muscular hypotonia; and a furrow between the first and second toes. There was evidence of some seizure disorder and reduced motor activity.

Additional findings on present examination Head: microcephalic, with a $45 \mathrm{~cm}$ circumference. The occiput was slightly flattened. Fontanelles were not palpable. Hair was blonde and the hairline normal. External ears were small, low-set, and of unusual configuration. The right ear was peaked at the helix, appearing elf-like. The left ear was square in shape with a tightly-rolled pinna. Ear canals were tortuous although the drums were normal. Neck control, tone, and shape were normal.

Facies: The forehead was prominent with a slight trigonocephaly. The eyebrows were distinctive with the medial halves growing upward and medially, with synophrys, and the lateral halves thinned out and growing outward and downward in a normal manner. Orbital ridges were very prominent and the nasal bridge was quite broad. The palpebral fissures were slanted downward; and the eyes were asymmetrical and sunken. A good pupillary and red reflex were elicited. A funduscopic examination could not be performed. The nose was bulbar, with a septal prominence and irregular nares. There was irregularity of the vermilion border of the upper lip which was also scarred from earlier cleft lip repair. Oral examination revealed congenital absence of upper incisors and deformity of the alveolar ridges. A midline soft palate defect was present extending marginally into the hard palate with a well-demarcated line extending to the apex of the high-arched palate. The pharynx and tongue were normal.

Chest: The intercostal spaces were prominent but the lung fields were clear. The heart appeared normal with a normal sinus rhythm and no evidence of murmurs or rubs. All peripheral pulses were palpable.

Abdomen: The liver and spleen were not enlarged. An umbilical hernia was demonstrated, and the general musculature was very tight. Inguinal scars were present from earlier hernia repair.

Genital and rectal: External examination was unremarkable except for a deep dimple over the sacral area.

Extremities: Deep tendon reflexes were bilaterally symmetrical. Babinski and Moro's reflexes were absent. Bilateral clinodactyly was present with scars on the ulnar aspect of one hand as a result of surgical removal of the supernumerary digit. The fingers were long, tapered, and delicate. The fingernails were hyperconvex. The thumbs and great toes were quite large bilaterally. The second and fourth toes overrode the third toes bilaterally. The feet assumed a talipes equinovalgus position at rest with pronounced pes planus. The musculature was poorly developed and was characterized by intermittent hypertonia and hypotonia.

Skin: Texture was normal. Numerous midline capillary haemangiomas were present being particularly prominent in the posterior neck region extending onto the area of the occiput and down the midline into the interscapular area. Some were also present about the forehead and temporal areas.

Dermatoglyphs: Right hand: (1) thumb, arch; (2) arch; (3) ulnar loop; (4) radial loop; (5) radial loop. Left hand: (1) thumb, arch; (2) arch; (3) ulnar loop; (4) whorl; (5) whorl. Axial triradii could not be measured because of poorly defined dermal patterns on both palms.

Developmental history. The child ambulates by means of rolling over. She appears to enjoy pulling hair and is conscious of family members and various objects about the home. She sucks her fingers and thumbs continuously and clinches fists when angry. She is able to sit unsupported for a minute at a time and is reported to be able to pull herself up to the side of the bed. Her food is primarily in liquid form as she objects strenuously to grainy foods. Television, radio, and music as well as attention from various members of the family are enjoyed. Her Vineland Social Maturity Scale Age was determined to be 5 to 6 months. She has had only one severe respiratory infection and is in reasonably good health except for nutrition. Grand mal seizures which developed at 1 year of age are well controlled on phenytoin and phenobarbitone.

\section{Cytogenetic studies}

Chromosome analyses of the patient and her parents were performed on peripheral blood lymphocytes incubated for 66 hours in McCoy's 5A, F-10, and RPMI 1640 culture media, according to conventional procedures. Metaphase chromosome spreads were G-banded using a modified stain technique incorporating trypsin and Leishman's stain. Suitable spreads were photographed on Kodak High Contrast Copy film using a Zeiss Photomicroscope III. A total of 30 apparently intact cell spreads were photomicrographed on each individual. Careful examination of the photographs was carried out for both interchromosomal and intrachromosomal anomalies in all three individuals.

Fig. 1 is a representative karyotype seen in the propositus and clearly exhibits the additional D-group chromosome, which on the basis of internal morphology corresponds to the number 13 chromosome according to the Chromosomes: Paris Conference (1971). Fig. 2 is an enlargement of the D-group chromosomes only in three other cells depicting the similar morphology of the three number 13 chromosomes and the absence of any apparent internal changes thereto. An additional 70 metaphase spreads of the index patient were examined microscopically with the following results. Seven D- 

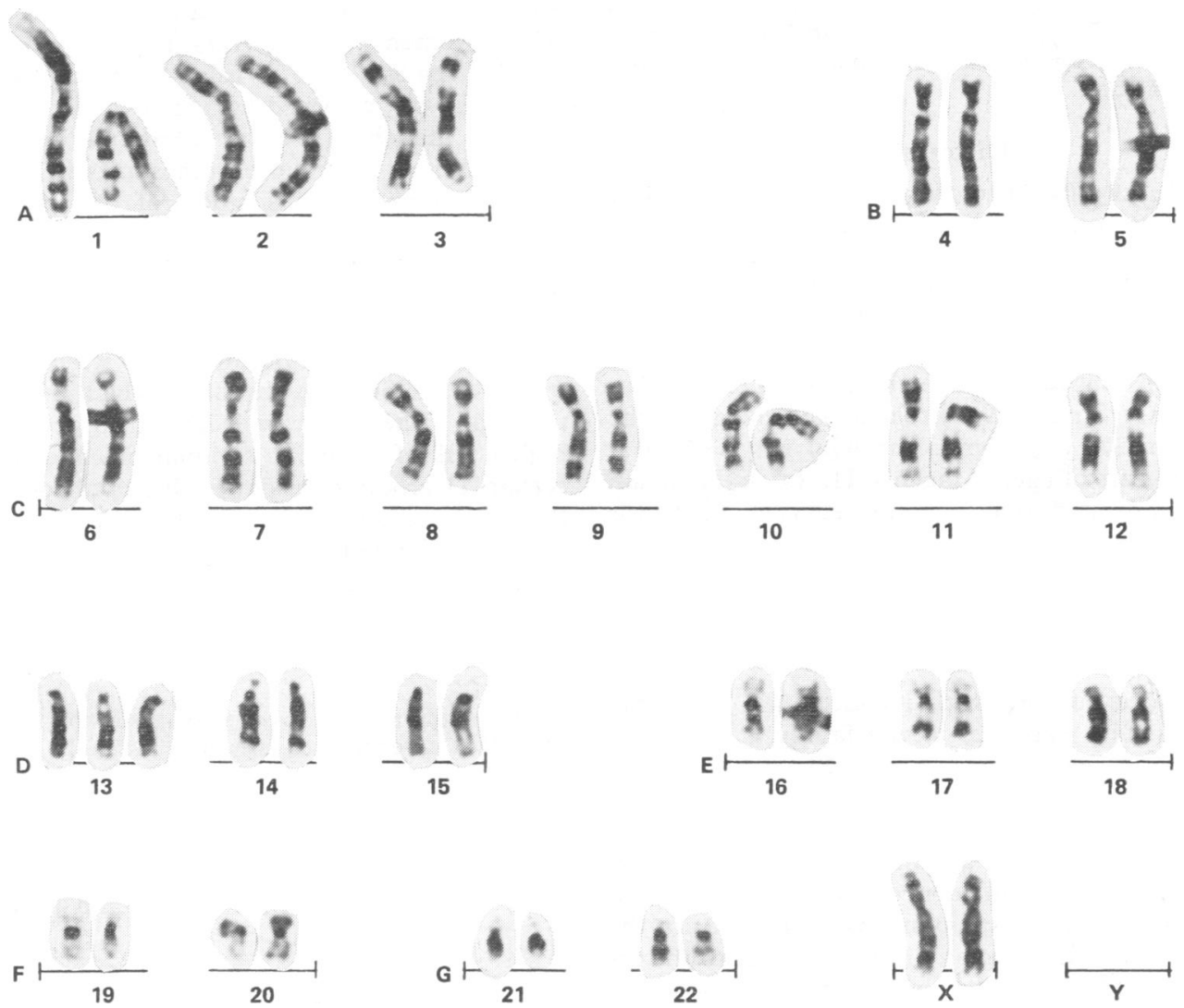

Fig. 1. A complete karyotype of the propositus. The chromosomes were G-banded with trypsin and Leishman's stain and reveal no intrachromosomal abnormalities. The additional chromosome in the $\mathrm{D}$ group is clearly a number 13.

group chromosomes were found in 62 of the cells. Eight metaphase spreads had only 6 D-group chromosomes. Banded chromosome analysis indicated that six of the eight had three number 13 chromosomes. Chromosome banding was not adequate in the remaining two spreads to rule out or confirm the presence of the additional number 13 chromosome. In all, 98 out of 100 cells analysed in the patient were found to be trisomic for the number 13 chromosome.

Our study revealed that the propositus was trisomic in all cells examined with a chromosomal formula of $47, \mathrm{XX},+13$. Since no cells were conclusively shown to lack the additional number 13 chromosome, the evidence against mosaicism in the index patient is substantial. Analyses of both parents revealed entirely normal Dgroup karyotypes which are, therefore, not shown.

Parental chromosome banding was not of sufficient quality to allow accurate attribution of the additional number 13 chromosome seen in the patient. The parents were generally uncooperative and would not permit a second peripheral blood study necessary for fluorescence examination for satellite markers. The

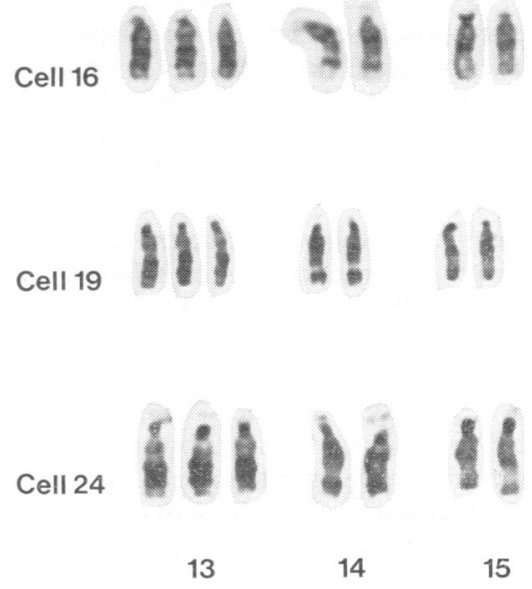

FIG. 2. A partial karyotype of the D group chromosomes in three other cells. The correspondence of the banding in the three number 13 chromosomes is obvious. 
parents also refused permission to undertake a skin biopsy and tissue culture karyotype analysis of the propositus to determine whether or not mosaicism existed in other tissues.

\section{Discussion}

It is most difficult to compare our case of trisomy 13 to many of those reported as trisomy $D$, etc. For this reason, we will not enumerate the many findings described by others (Bergsma, 1973; Goodman, and Gorlin, 1970; Holmes et al, 1972; Smith, 1970) which include cases which may not be trisomy 13 but rather of the number 14 or 15 chromosomes. Smith (1970) related knowledge of one case of trisomy 13 syndrome who survived to at least 33 years of age. Magenis, Hecht, and Milham (1968) indicated that a better survival prognosis was to be expected in patients with trisomy 13 translocations or mosaicism for both normal and trisomic cell lines. In any event, both survival and developmental prognoses for these individuals are very poor.

Extended survival with its incidental emotional and monetary expenses to the family is, however, possible in complete trisomy 13 , as is clearly established with this case. The risk of recurrence is also possibly greater than might be expected. This is indicated by a number of recent reports concerned with the incidence of trisomy 13 in both newborns as well as spontaneous abortions. In the first instance, the relation of maternal age to the incidence of $\mathrm{D}$ trisomy has been reviewed, and it has been found (Magenis et al, 1968) that the highest frequency of affected births was in the 35- to 39year age group to which the proband's mother belonged. It is possible that some of the conditions or genetic processes which predispose meiotic nondisjunction in E- and G-group chromosomes, which are known to increase in frequency with advanced maternal age and certain genetic backgrounds, are also active in increasing the frequency of trisomy 13.

Other evidence suggests that there is a substantial tendency for recurrence of trisomy D states. Carr (1965), in his series of spontaneous abortions, reported that $13.6 \%$ of the conceptuses studied had $\mathrm{D}$ trisomy and that four of the six mothers (66\%) had had a previous abortion or stillbirth of unknown chromosomal status. Boué and Boué (1973) found a comparable incidence rate in their study of the chromosome complements of consecutive abortuses in 43 mothers. Fifteen of the 84 abortuses $(17.8 \%)$ had trisomy $\mathrm{D}$ on karyotypic analysis. Two of the 13 mothers (15\%) involved had trisomy $D$ abortuses in both the initial and subsequent pregnancies. The mean maternal age of the involved women was 33.7 years.

Lauritsen et al (1972), using fluorescent chromosome analysis, reported evidence which tentatively suggests that there may be differential involvement of the various D-group chromosomes in spontaneous abortions. In his study of 68 spontaneous abortuses, he found 34 which were chromosomally abnormal. Three of these $(8.8 \%)$ had trisomy $\mathrm{D}$. All of the trisomy $\mathrm{D}$ abortuses had an additional number 15 chromosome.

This, then, raises questions as to which D-group trisomies are likely to abort and which may survive to term. There may well be a disproportionately higher risk of recurring spontaneous abortion with certain D-group aneusomies than with others. If this is borne out in subsequent studies, information regarding the chromosomal complement of the first abortus could be of considerable practical and medical significance to both the prospective parents as well as to the physician attending the family.

The authors wish to express their appreciation to Miss M. Carver for her assistance in family counselling and to Miss B. A. de La Houssaye, Mrs. M. Garcia, Mr. D. Hale, and Mr. J. Tsai for their technical assistance.

\section{B. Mankinen and J. W. Sears \\ Genetics Service, Texas Department of Mental Health and Mental Retardation, Denton State School, Denton, TX 76202, USA}

\section{REFERENCES}

Bergsma, D. (1973). (Ed.) Birth Defects Atlas and Compendium, p. 1006. Williams and Wilkins, Baltimore.

Boué, J. G. and Boué, A. (1973). Chromosomal analysis of two consecutive abortuses in each of 43 women. Humangenetik, 19, 275-280.

Carr, D. H. (1965). Chromosome studies in spontaneous abortions. Obstetrics and Gynecology, 26, 308-326.

Casperson, T., Zech, L., and Johansson, C. (1970). Differential binding of alkylating flurochromes in human chromosomes. Ex- 을 perimental Cell Research, 60, 315-319.

Chromosomes: Paris Conference (1971). Standardization in $N$ human cytogenetics. Birth Defects: Original Article Series 8, No. 7, 1972, p. 46. National Foundation-March of Dimes, New York.

Goodman, R. M. and Gorlin, R. J. (1970). The Face in Genetic CU Disorders, p. 169. C. V. Mosby, St. Louis.

Holmes, L. B., Moser, H. W., Halldorsson, S., Mack, M. S., Pant, S. S., and Matzilevich, B. (1972). Mental Retardation-An Atlas of Diseases with Associated Physical Abnormalities, p. 430. Macmillan, New York.

Lauritsen, J. G., Jonasson, J., Therkelsen, A. J., Lass, F., Lindsten, J., and Petersen, G. B. (1972). Studies on spontaneous abortions. Fluorescence analysis of abnormal karyotypes. Hereditas, 71, 160-163. 
Magenis, R. E., Hecht, F., and Milham S. Jr. (1968). Trisomy 13 (D) syndrome: studies on parental age, sex ratio, and survival. fournal of Pediatrics, 73, 222-228.

Moorhead, P. S., Nowell, P. C., Mellman, W. J. Battips, D. M., and Hungerford, D. A. (1960). Chromosome preparations of leukocytes cultured from human peripheral blood. Experimental Research, 20, 613-616.

Seabright, M. (1971). A rapid banding technique for human chromosomes. Lancet, 2, 971-972.

Smith, D. W. (1970). Recognizable Patterns of Human Malformation, p. 368 . W. B. Saunders, Philadelphia.

Sumner, A. T., Evans, H. J., and Buckland, R. A. (1971). New technique for distinguishing between human chromosomes. Nature (London) New Biol., 232, 31-32.

\section{Familial ureteric bud anomalies}

Summary. A family is described in which various renal anomalies occurred. The condition is considered to represent an autosomal dominantly inherited instability' of the ureteric bud.

There have been a number of reports on the occurrence of variable anomalies of ureteric bud development within a kindred (Atwell et al, 1974; Dietel, 1964; Nillson, 1960; Rossle, 1942). We report here the rare finding of double kidney, unilateral renal agenesis, and horseshoe kidney in two generations of one family.

\section{Clinical findings}

The proband, II.1, was the first daughter of unrelated and healthy Caucasian parents aged 29 and 45 years, respectively. Pregnancy and parturition were uncomplicated and the birthweight was $2900 \mathrm{~g}$. At routine neonatal physical examination (technique of Museles $e t a l, 1971$ ) the left kidney was not palpable; no other defects were detected. Intravenous pyelography (Fig. 1) failed to detect functioning renal tissue on the same side. The presumptive diagnosis was left renal agenesis. At follow-up no additional anomalies were detected. The karyotype was that of a normal female. The second pregnancy resulted in the birth of an apparently healthy boy, II.2, following a normal pregnancy and parturition. Birthweight was $3410 \mathrm{~g}$. Physical examination revealed a horseshoe kidney as the only abnormal finding, and both renal scan (Fig. 2) and intravenous pyelography confirmed the diagnosis.

As a result of the above findings the parents underwent radiological studies of the kidneys. The father was normal but in the mother, I.1, a right double kidney and collecting system were disclosed (Fig. 3).

There was no family history of renal disease or of hypertension. The mother's parents and only sib refused to undergo pyelography.

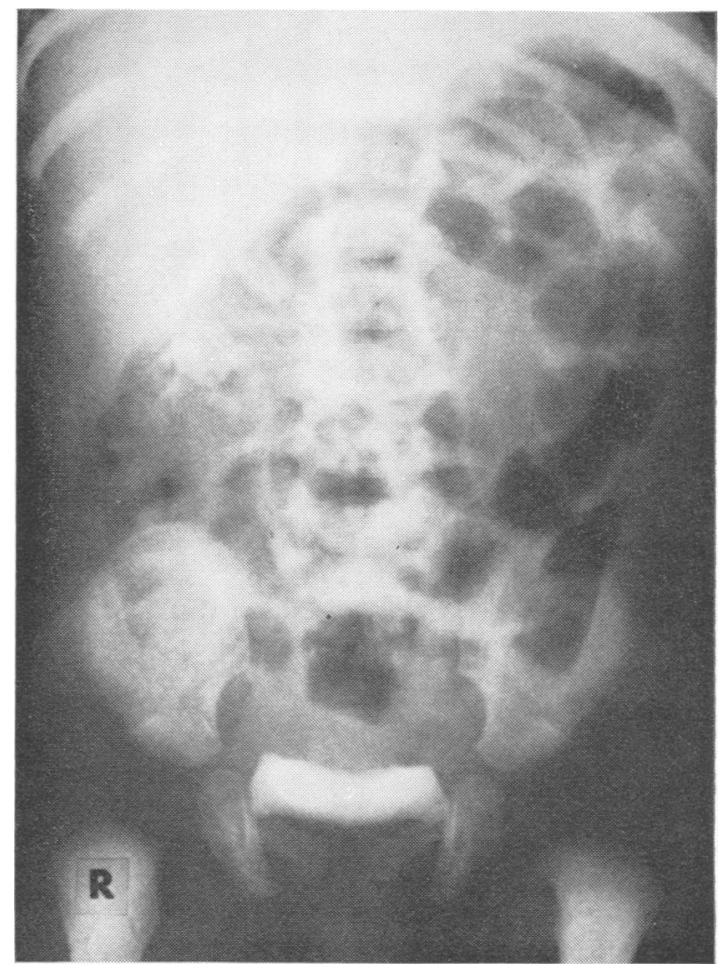

FIG. 1. II.1. Intravenous pyelography showing failure of excretion of contrast medium by left kidney.

\section{Discussion}

Malformations arising from the ureteric bud are common and, not infrequently, more than one instance of a single anomaly is found in a kindred (Atwell et al, 1974; Holmes, 1972; Lenz, 1964; Warkany, 1971). The occurrence of varying anomalies within a kindred is rare, and we have found only four reported instances in which two or more of the three above anomalies were found together. One of these examples was associated with Fanconi's anaemia (Nillson, 1960).

The present family is of interest from the aspects of both aetiology and pathogenesis. Discussion of the latter requires consideration of the embryology of the kidney and collecting system.

The human definitive kidney (metanephros) arises from two embryonic sources. The intermediate (metanephric) mesoderm which differentiates into the nephron and connective tissue of the kidney; and the ureteric (metanephric) bud which arises from the mesonephric (Wolffian) duct, and gives rise to the collecting system of the kidney (Potter, 1972; Warkany 1971). 